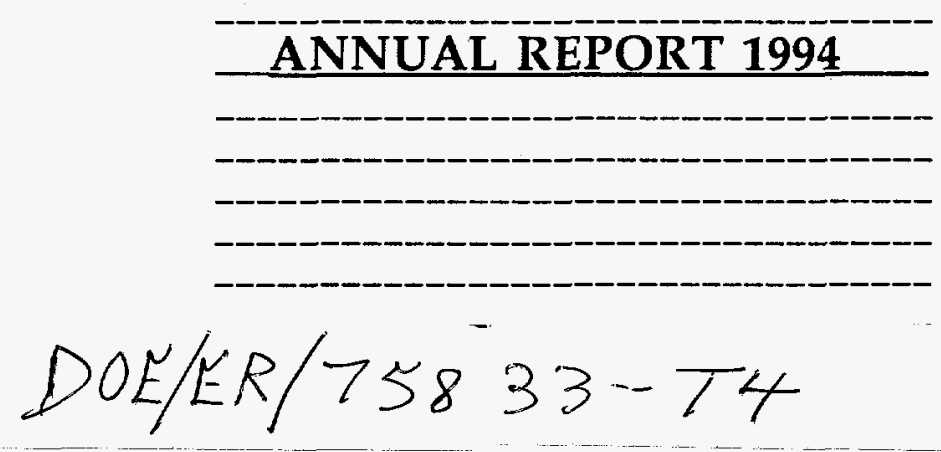

Science and Engineering Alliance, Inc.

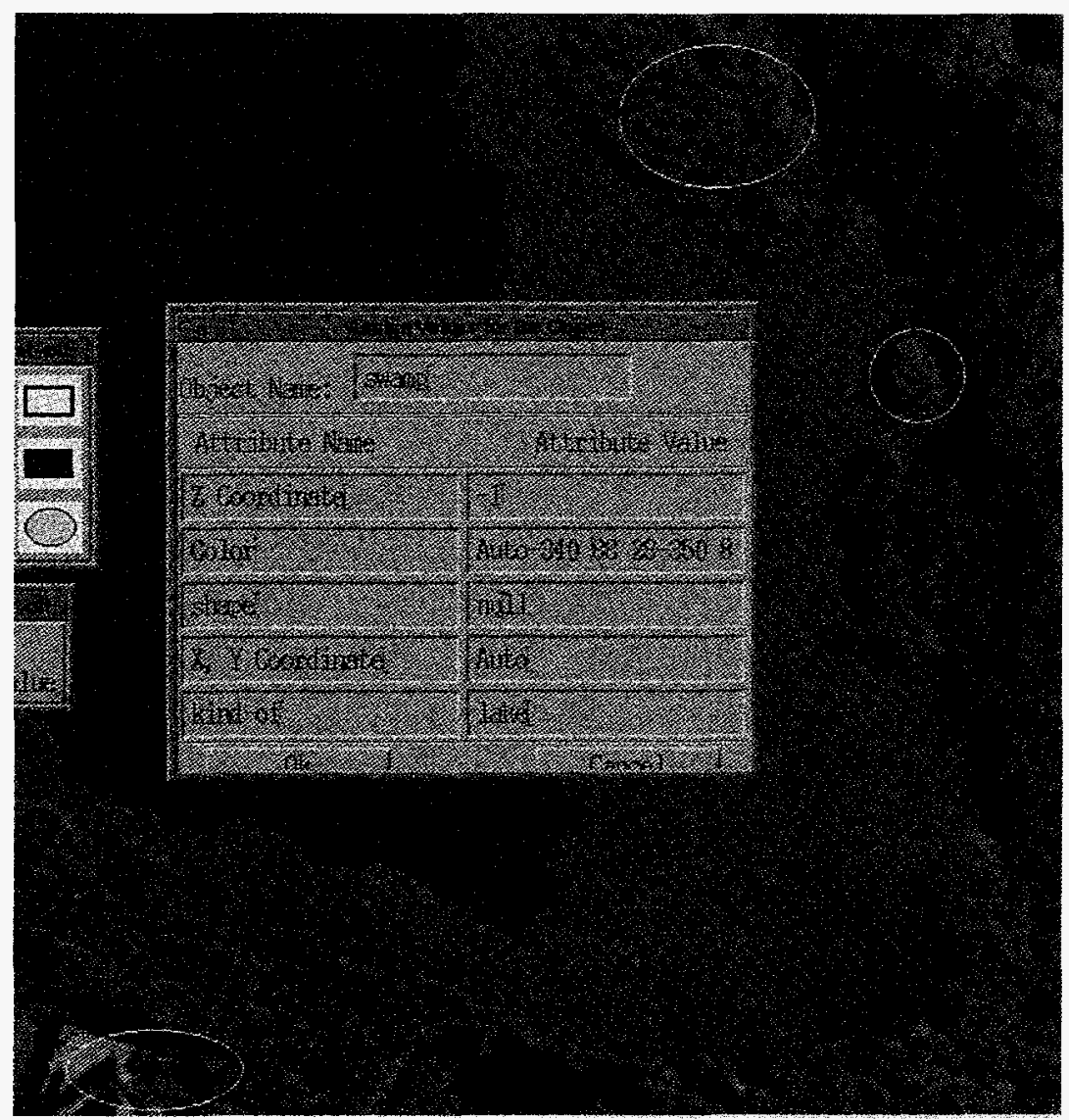

AAMUOJSUOPVAMUOSUBR ${ }^{\circ} L L N L$ JSUOPVAMUOSUBR'LLNLOAAMU

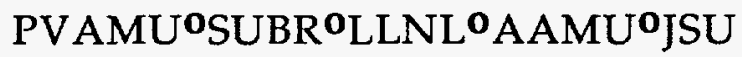
SUBR ${ }^{\circ} L L N L{ }^{\circ} A A M U O J S U O P V A M U$ LLNL ${ }^{\circ} A A M U^{\circ}{ }^{\prime} U^{\circ} U^{\circ} P V A M U^{\circ} S U B R$ AAMUOJSUOPVAMU'OSUBR ${ }^{\circ} L L N L$ JSUOPVAMUOSUBR'LLNLOAAMU

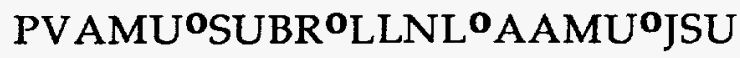

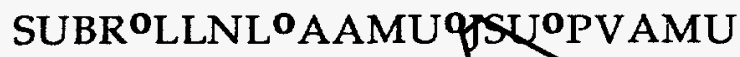
LLNL'AAMUOJSUOP YAMUESUBR AAMUOJSUOPXAMU OSWBY LIY JSUOPVAMYOSS BROLL LLAKMU PVAMUQSURRO ONLO A IRUOJSU SUBBPLLNS O AMY YSU OPVAMU LYTLAAMUESU O VAMUOSUBR ALUOJSYOPVAMUOSUBROLLNL JSUOP AM JOSUBR ${ }^{\circ}$ LLNL $^{\circ} A A M U$ PVANUOS $B^{\circ}{ }^{\circ} L L N L{ }^{\circ} A A M U^{\circ} J S U$ SUBR OLNLOAAMUOJSUOPVAMU

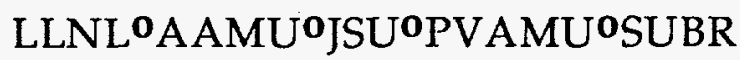
AAMUOJSUOPVAMU'SUBR ${ }^{\circ} L L N L$ JSUOPVAMUOSUBR'LLNL ${ }^{\circ} A A M U$ PVAMUOSUBR ${ }^{\circ} L L N L{ }^{\circ}$ AAMUOJSU SUBR $^{\circ}{ }^{\circ L N L}{ }^{\circ}$ AAMU'OJSUOPVAMU LLNL ${ }^{\circ} A A M U O J S U O P V A M U O S U B R$ AAMUOJSUOPVAMUOSUBR'LLNL JSUOPVAMU ${ }^{\circ}$ SUBR $^{\circ}{ }^{\circ}$ LNL $^{\circ}$ AAMU 


\section{DISCLAIMER}

This report was prepared as an account of work sponsored by an agency of the United States Government. Neither the United States Government nor any agency thereof, nor any of their employees, makes any warranty, express or implied, or assumes any legal liability or responsibility for the accuracy, completeness, or usefulness of any information, apparatus, product, or process disclosed, or represents that its use would not infringe privately owned rights. Reference herein to any specific commercial product, process, or service by trade name, trademark, manufacturer, or otherwise does not necessarily constitute or imply its endorsement, recommendation, or favoring by the United States Government or any agency thereof. The views and opinions of authors expressed herein do not necessarily state or reflect those of the United States Government or any agency thereof.

\section{Cover Caption}

A sample window from SemCap (Semantics Capture) Tool is shown being used to semi-automatically capture the content in the image of a Louisiana swampland. The primitive features and logical features of the objects (such as the swamp marked in red on the top left, forest outlined by an ellipse on the top right, oil tank on the bottom left, etc.) are being captured and stored into the logical image database by the SemCap.

SemCap is an image indexing tool for distributedcontent-based image storage retrieval systems for scientific users. This has been developed as a part of the DOE-funded JSU-SEA-HPCC project (in collaboration with another ARPA-funded project), of building an integrated scientific computing environment. SemCap is versatile in the sense that it can be used across several domains including scientific domains. SemCap takes a hybrid approach to feature extraction. Typically, primitive features are extracted automatically or semiautomatically while the logical image features are derived manually. 


\section{DISCLAIMER}

Portions of this document may be illegible electronic image products. Images are produced from the best available original document. 
Science and Engineering Alliance, Inc.

Contents

1 Table of Contents

2 Overview

3 Chairman's Letter

4 Executive Director's Message

FY94 Achievements \& Activities

$5 \quad$ High Performance Computing

5 Other Special Projects

5 Linking SEA To Internet

6 Summer Research at LLNL

7 Student Support

8 Outreach

$8 \quad 1995$ Goals

$9 \quad$ Financial Statements

Impact Data

12 Programmatic

13 Awards

14 Graduation

15 Leadership
AAMU•JSU•PVAMU•SUBR•LLNL JSU॰PVAMU॰SUBR॰LLNL•AAMU PVAMU•SUBR॰LLNL•AAMU•ISU SUBR•LLNL•AAMU•JSU•PVAMU LLNL•AAMU•JSU•PVAMU•SUBR AAMU•JSU•PVAMU•SUBR•LLNL JSU•PVAMU•SUBR•LLNL•AAMU PVAMU•SUBR・LLNL•AAMU•ISU SUBR•LLNL•AAMU•JSU•PVAMU LLNL•AAMU•JSU•PVAMU•SUBR AAMU•JSU•PVAMU•SUBR॰LLNL JSU•PVAMU॰SUBR•LLNL•AAMU PVAMU॰SUBR•LLNL•AAMU•JSU SUBR॰LLNL•AAMUJSU•PVAMU LLNL•AAMU•JSU•PV AMU•SUBR AAMU॰JSU॰PV AMU॰SUBR・LLNL JSU•PVAMU•SUBR•LLNL•AAMU PVAMU•SUBR・LLNL•AAMU•JSU SUBR•LLNL•AAMU•JSU•PVAMU LLNL•AAMU•JSU•PV AMU•SUBR AAMU॰JSU•PVAMU॰SUBR •LLNL JSU•PVAMU•SUBR•LLNL•AAMU PVAMU•SUBR・LLNL•AAMU•JSU SUBR•LLNL•AAMU•JSU•PVAMU LLNL•AAMU•JSU•PVAMU•SUBR AAMU•JSU•PVAMU॰SUBR•LLNL JSU•PVAMU•SUBR LLLNL•AAMU PVAMU•SUBR•LLNL•AAMU•JSU SUBR•LLNL•AAMU•JSU•PVAMU LLNL•AAMU•JSU•PVAMU•SUBR 


\section{Science and Engineering Alliance, Inc.}

\section{Overview}

The Science and Engineering Alliance (SEA) was formed in 1990. The goal of the SEA is to foster and encourage collaborative research among the Alliance members. Collaborative research enhances the production of wellqualified scientists and engineers graduating from the SEA member institutions. These students will become contributing participants in the United States technical workforce now and into the next century. The SEA consist of four historically black colleges and universities (HBCUs) and a national laboratory.

The four HBCU institutions are:

- Alabama AEM University ( $A A M U$ )

Normal, AL

(1890 Land Grant University)

- Jackson State University (JSU)

Jackson, MS

(Comprehensive Urban University)

- Prairie View A\&M University (PVAMU)

Prairie View, TX

(1890 Land Grant University)

- Southern University and AEM College (SUBR)

Baton Rouge, LA

(1890 Land Grant University)

The national laboratory is:

- Lawrence Livermore National Laboratory (LLNL) Livermore, CA

The SEA is a non-profit consortium. The SEA collaborates on research projects with government agencies, national laboratories, private foundations, industry, and other universities in a broad range of scientific and technical areas.

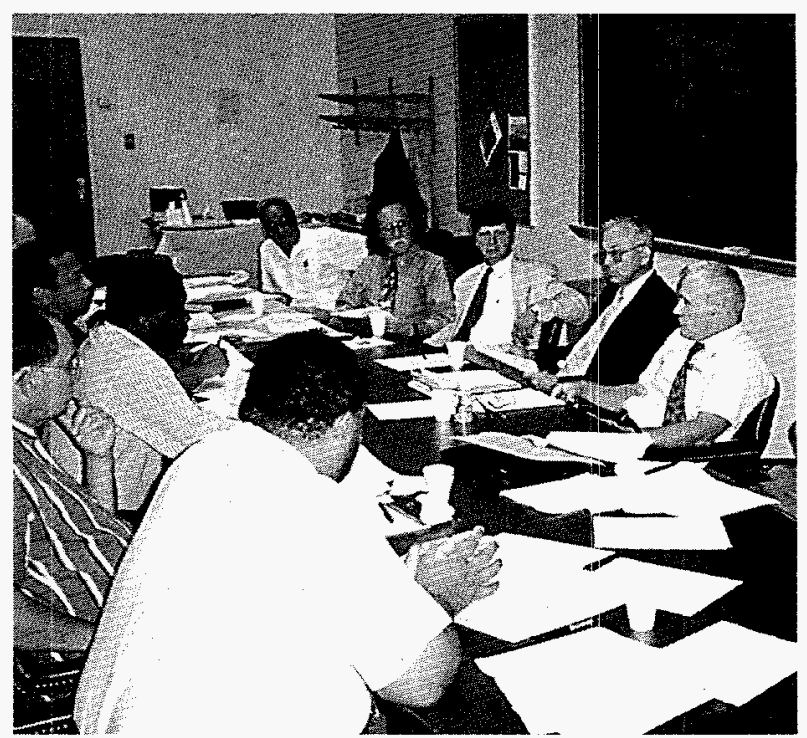

Financial Highlights (No salaries included)

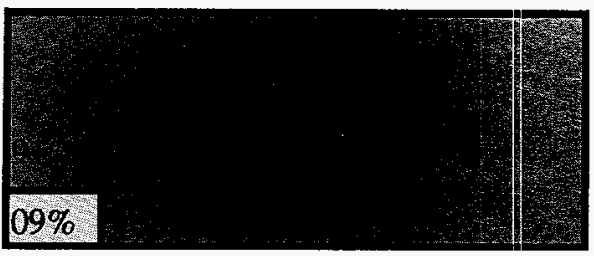

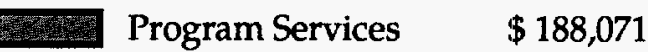

Management \& Gen. $\quad \$ 17,751$ 


\section{Letter from the Chairman}

The SEA is fast becoming the standard by which the member institutions conduct collaborative research. The process of bringing together technical faculty from each institution with an interest and commitment to work together (i.e., Design Teams) is beginning to bear fruit.

During 1994, the Alliance received its first major research award. The award is in the area of high performance computing and communications. It affords the members the opportunity to play an important role in the development of the nation's National Information Infrastructure (NII) activities.

As the SEA continues to use its Design Teams to foster collaborative interactions of the caliber of the high performance computing research initiative, the faculty and students will receive greater benefits. Ultimately, America's technical workforce will share in the rewards of the SEA successes.

Two of the benefits are observed immediately: (1) a better prepared entry level technical worker that translates into increased productivity; and (2) a reduction in the training dollars that employers need to invest to bring entry workers to an acceptable level of performance in their new technical assignments.

Looking toward 1995, we are convinced that the involvement of the SEA in high performance computing and communications will expand into other technical areas. Such focused collaborations help to strengthen the collective body and the individual science and engineering programs at each member institution.
SUBR will continue its involvement in the SEA. This will be achieved with a clear understanding of the long-term benefits of engaging in such a resource-sharing Alliance.

Marvin L. Yates

Marvin L. Yates

Chairman, SEA Executive Board

Chancellor, SUBR

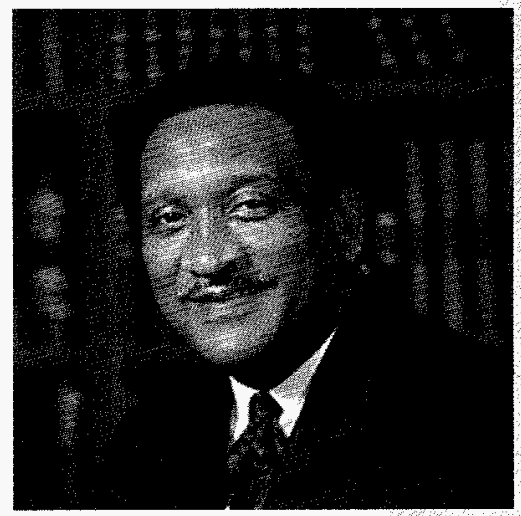




\section{Message from the Executive Director}

This Annual Report focuses on Accountability. To meet the goals and objectives set for the SEA, it is important to constantly ask "what is being accomplished?" The Executive Board and Steering Committee believes that this question must be assessed annually.

SEA believes that obtaining research grants, conducting teacher enhancement workshops, and providing financial support are major accomplishments. But accountability requires an explanation on how the resources were used to accomplish the mission. SEA's explanation is linked to its financial data.

Supporters need to know that as a result of the SEA Program, junior faculty members (assistant professors and other non-tenured staff), are enthusiastically engaged in research like SEA's High Performance Computing and Communications (HPCC) initiative. This kind of focused participation helps improve the productivity of young faculty. It also enhances their career path and creates additional options.

SEA faculty continue to participate in LLNL's ongoing summer program. The goal is to establish long-term, funded collaborative research at each academic institution. Graduate and undergraduate students continue to receive expert training working with their faculty advisors and mentors in the SEA Program at LLNL.

The recipients of our high school incentive awards continue to enroll in science and engineering programs internal and external to the SEA institutions.

Teachers that participate in our teacher enhancement workshops continue to provide positive feedback regarding their summer experience. During the academic year following the 1994 workshops, in addition to the participating teachers, feedback was obtained from principals, department chairs, and counselors. The administrators reported observing that students have become more enthusiastic and motivated about science and mathematics. Additionally, they reported observing a renewed teacher focus and greater interest in overall classroom activities. These assessments will continue.

Change and new direction are the order-ofthe-dlay. SEA will continue to demonstrate that the shared commitment of four HBCUs and a national laboratory, spread over five states, can make a difference.
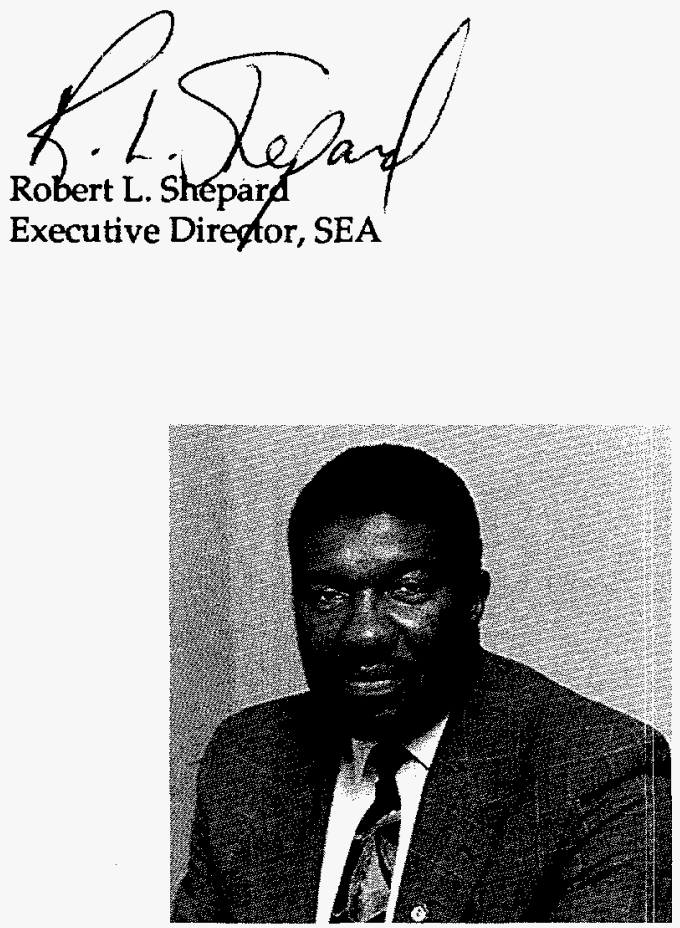


\section{High Performance Computing and Communications (HPCC)}

During FY94, the SEA was awarded its first major multiyear grant. The grant was awarded by the U.S. Department of Energy's (DOE) Office of Scientific Computing. The purpose of the grant is for the SEA to conduct research and training in the broad areas of high performance computing and communications (HPCC).

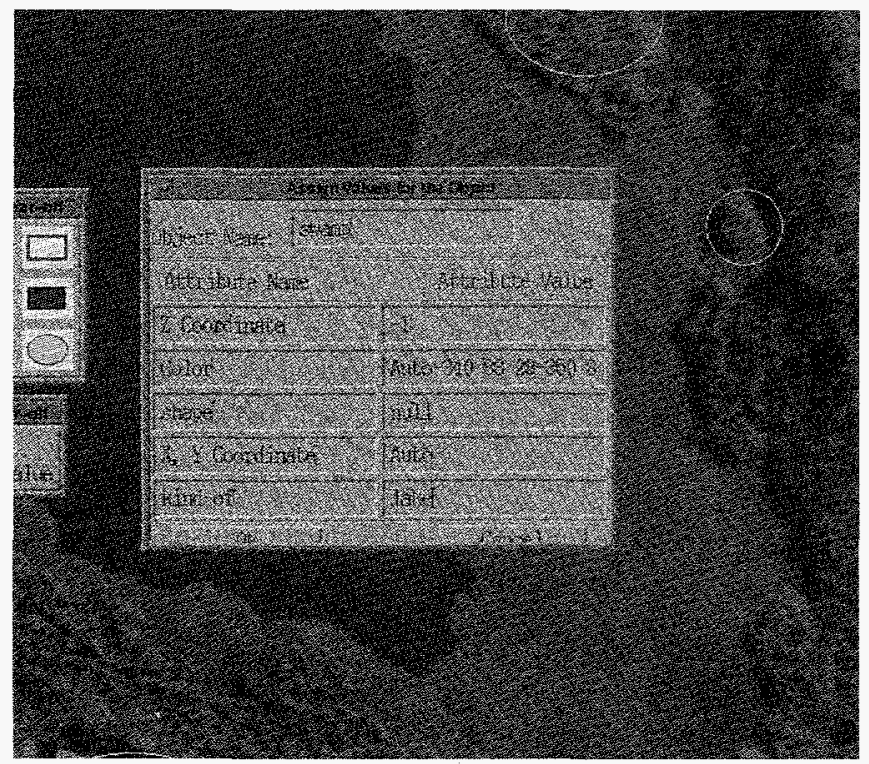

Specifically, SEA researchers have initiated work that will: (1) design, implement, test, and evaluate an integrated environment for scientific simulations; (2) address the issues of data management, database creation, and database management; (3) examine the use of optics and optical scientific database management systems (SDBMS) as a replacement of conventional SDBMS; and (4) study high performance computing in high-tc superconductivity.

The SEA HPCC initiative is expected to result in development of an Integrated Work Bench (IWB). The IWB will provide solutions to data management and retrieval problems. The project has well-defined and measurable goals and objectives.

\section{Other Special Projects}

The SEA project entitled "Installation of a Synchrotron Radiation and Beamline Facility at the J. Bennett Johnston, Sr. Center for Advance Microstructures and Devices for the Science and Engineering Alliance," was revised and resubmitted to DOE's Office of Energy Research for funding consideration. Also, a new project entitled "Community Environmental Justice Awareness and Training," was developed and submitted to the U.S. Environmental Protection Agency (EPA) for funding consideration.

Toward the end of FY94, DOE's Office of Science Education Program provided feedback on the SEA's infrastructure development project Phase III. The comments will be reviewed by the Steering Committee, and a response forwarded to DOE during FY95.

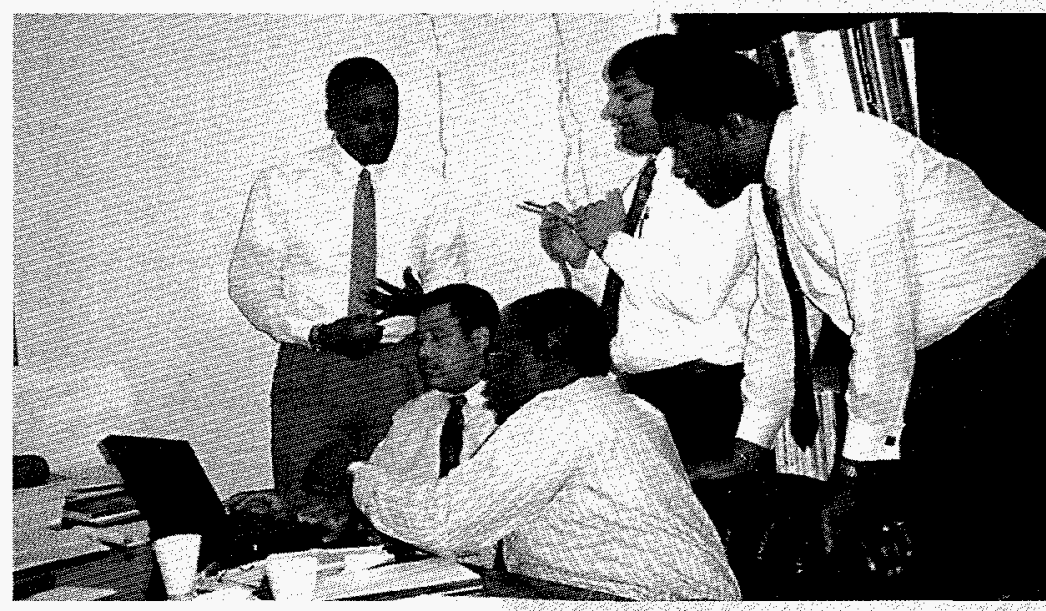

\section{Linking SEA Via The Internet}

During FY94, more SEA faculty members became linked to the Internet. The numbers are expected to increase as more faculty and students obtain and use Internet addresses. Using Internet has improved interaction among the institutions and resulted in a faster way to get SEA tasks accomplished. Presently, linkage consists primarily of members interacting via electronic mail. 
A geologist from PVAMU established a collaboration with researchers at LLNL's Site 300. The group studied the isotope hydrology of the gulf coast aquifer system involving Brazoria, Fort Bend, Harris, and Waller Counties, Texas. The goal of this research is to determine the flow system, age, and current ground water quality of this aquifer system.

A physicist from JSU participated in research to develop blazed multilayer coated gratings in LCAP.

Besides working with SEA faculty, several SEA students worked with ongoing LLNL research teams. These students were involved in projects designed to:

- Build a portable mass spectrometer

- Utilize X-ray fluorescence to detect trace dissolved elements in seawater

- Study the feasibility of using inelastic scattering of laser light to detect light elements

- Measure relativistic effects in highly stripped ions

- Enhance the spatial resolution of photon counting detectors

- Utilize two photon laser induced fluorescence techniques to detect rare gas atoms under atmospheric conditions

Twenty-two students and eight faculty members have participated in the LLNL program. Based on these interactions, four new spin-off research projects have been initiated at the academic institutions.

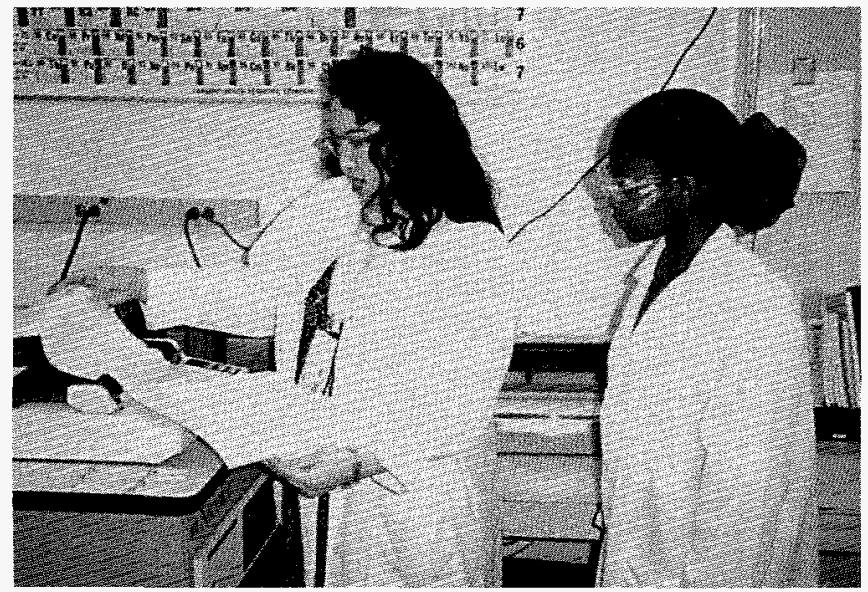

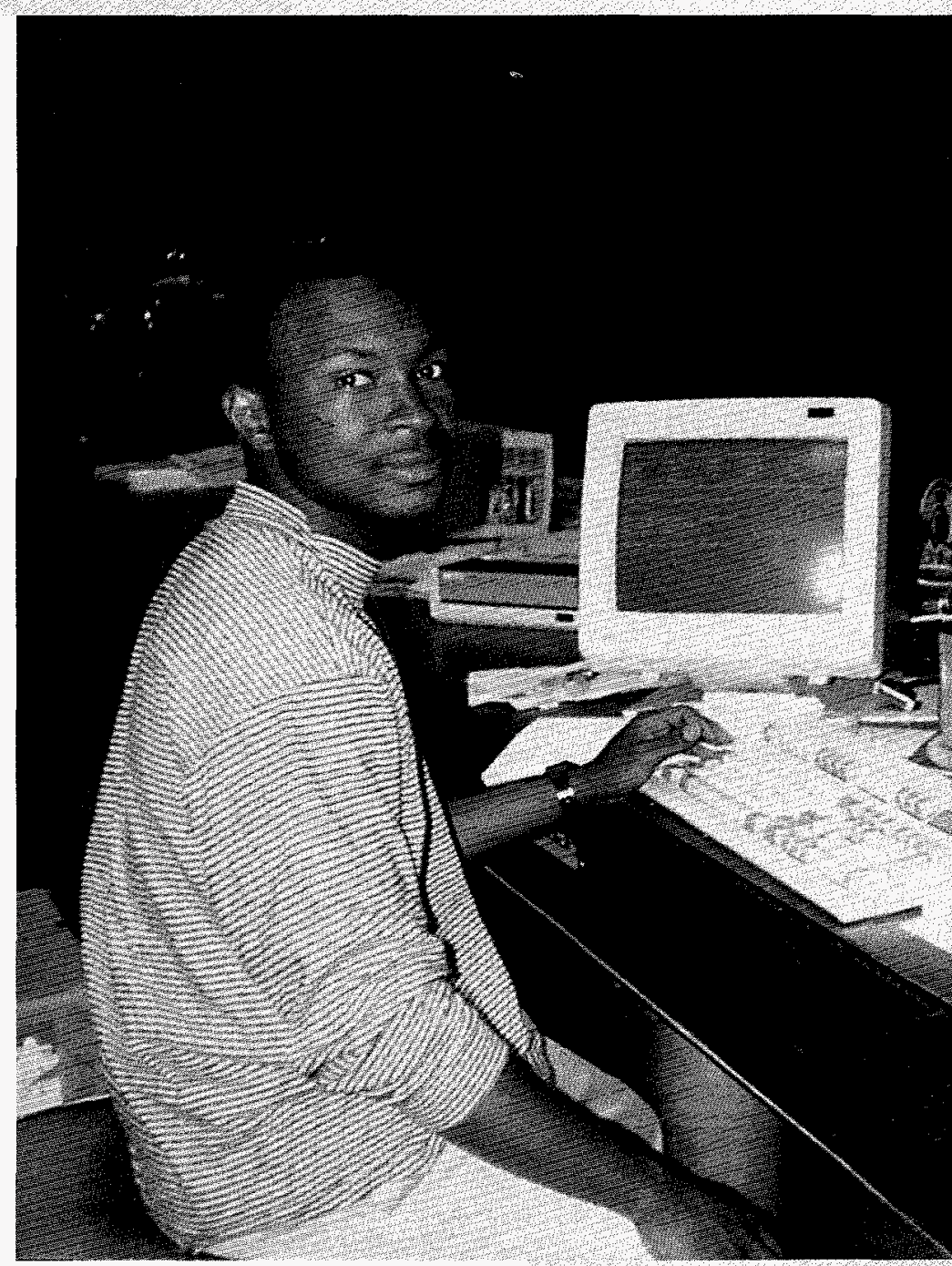

\section{Student Support}

During FY94, the SEA awarded 16 undergraduate scholarships and 16 high school incentive awards. These funds are used to supplement the education expenses of students that have demonstrated extraordinary talents toward science, engineering, and related subjects. This was the fourth year that the scholarship program has been in effect. This year the scholarships were presented at smaller events held at the individual institutions. The smaller events gave family and friends who would not be able to travel to Washington the opportunity to witness the activity. 


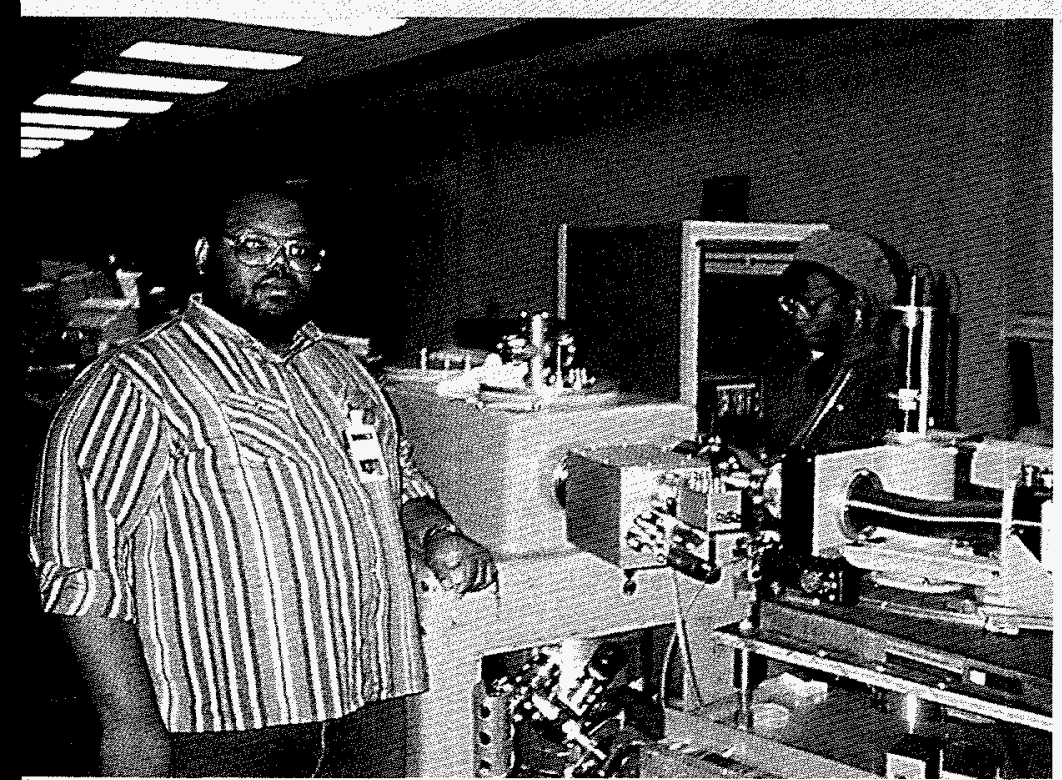

\section{Outreach}

A total of 81 high school teachers participated in SEA's teacher enhancement workshops during the summer of 1994. For the first time, feedback was obtained from the participating teachers' supervisors and other key staff. These included principals, department chairs, and counselors. The administrators reported observing improvements in student enthusiasm and motivation toward science and mathematics. They also reported observing renewed teacher focus and interest in their classroom activities. It is expected that all of this will ultimately be reflected in student's standardized test scores.

The Federal Information Exchange/Minority OnLine Information System (FEDIX/MOLIS) continues to serve as the primary means by which SEA extends its services to others, especially to smaller HBCUs. Many of the inquiries in FY94 came from institutions interested in enhancing their science education programs. Interacting with the institutions continue to reveal the need for conducting need assessments. The assessment results will reflect how the existing infrastructure can be strengthened over time. To be successful, these institutions must develop strategic plans to aid their planning for the future.

\section{FY 95 Goals}

The SEA will continue to develop special research projects to enhance the member's institutional infrastructure. These projects will significantly advance knowledge in the physical sciences and engineering. The SEA will continue to serve as a vehicle to promote collaborative research. Also, SEA will continue to provide enrichment opportunities for junior faculty members and new students as special projects are funded.

The goal is to secure at least two funded research projects through SEA. Additionally, steps will be taken to involve more SEA faculty and students in the LLNL summer research program. SEA will host at least one technical seminar or colloquium at each of the Alliance institutions. LLNL and other organizations with the appropriate technical expertise will be included as participants. Additionally, at least one SEA course offering will be initiated using video teleconferencing.

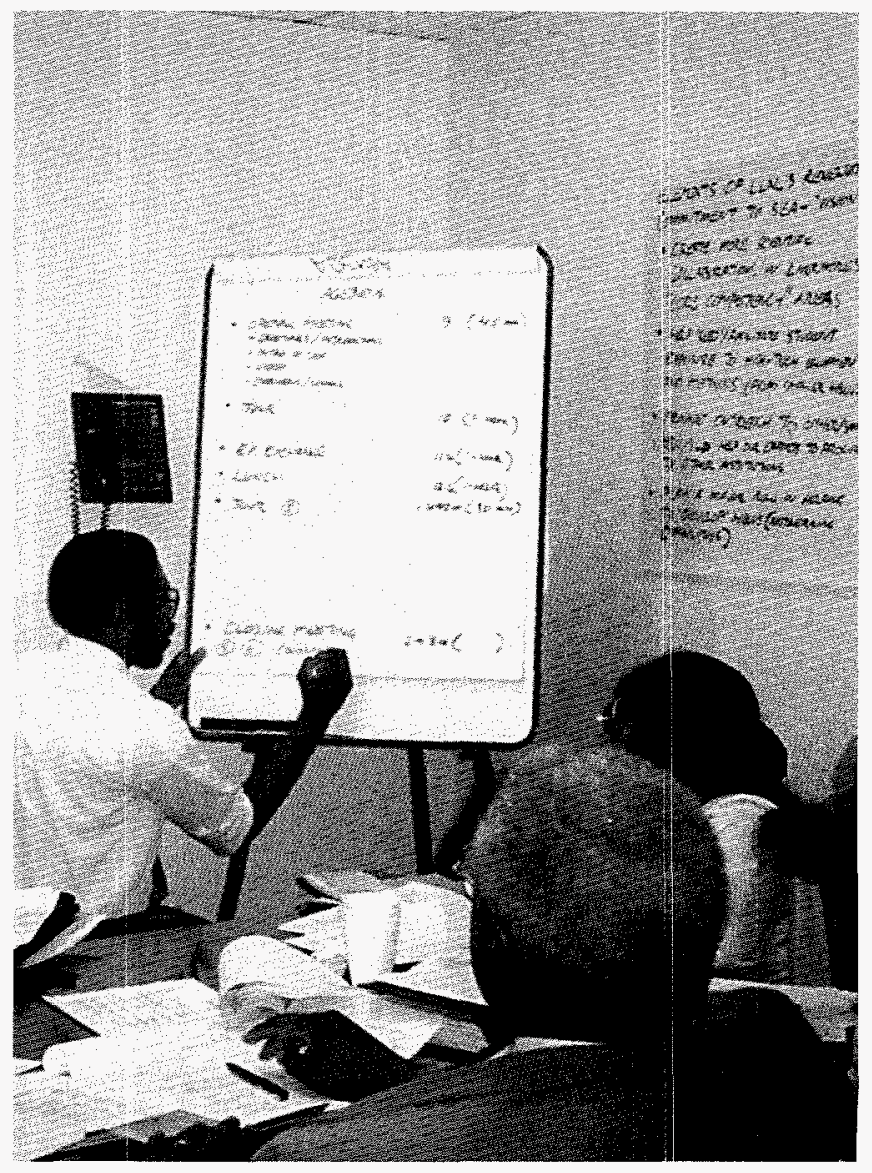




\title{
Balance Sheet
}

As of September 30, 1994

(SEA, Inc. not-for-profit corporation)

\section{ASSETS}

\author{
CURRENT ASSETS \\ Cash \\ Receivables
}

$\$ 125,716$

60,080

185,796

\section{FIXED ASSETS}

Furniture, fixtures \& equipment

Less: accumulated depreciation

OTHER ASSETS

Deposits

1,800

TOTAL ASSETS

\section{LIAB ILITIES AND FUND BALANCE}

\section{CURRENT LIABILITIES}

Accounts payable

$\$ 3,436$

Accrued leave

Deferred revenue

FUND BALANCE taken, together with all footnotes and the detailed report of our independent auditors. 
Statement of Revenue, Expenses and Changes in Fund Balance For the Year Ended September 30, 1994

(SEA, Inc. not-for-profit corporation)

\section{SUPPORT}

DOE Grant

Other Grant \& Contributions

$\$ 150,958$

17,850

Donor Support

Contribution

12,450

510

Reimbursements

1,767

1,578

Interest Income

743

Total Support

185,856

\section{EXPENSES}

Program Services

DOE Grant

147,474

Scholarship Fund

Total Program Services

170,320

Supporting Services

Management \& General

17,751

Total Supporting Services

17,751

Total Expenses

188,071

Net Revenue over Expenditures

$(2,215)$

Fund Balance, October 1, 1993

93,884

Fund Balance, September 30, 1994

$\$ 91,669$

$==ニ==ニ=$

Administrative support for SEA was through a grant from LLNL to Jackson State University, and thus, is not reflected as part of SEA's financial statement. 


\section{Impact Data}

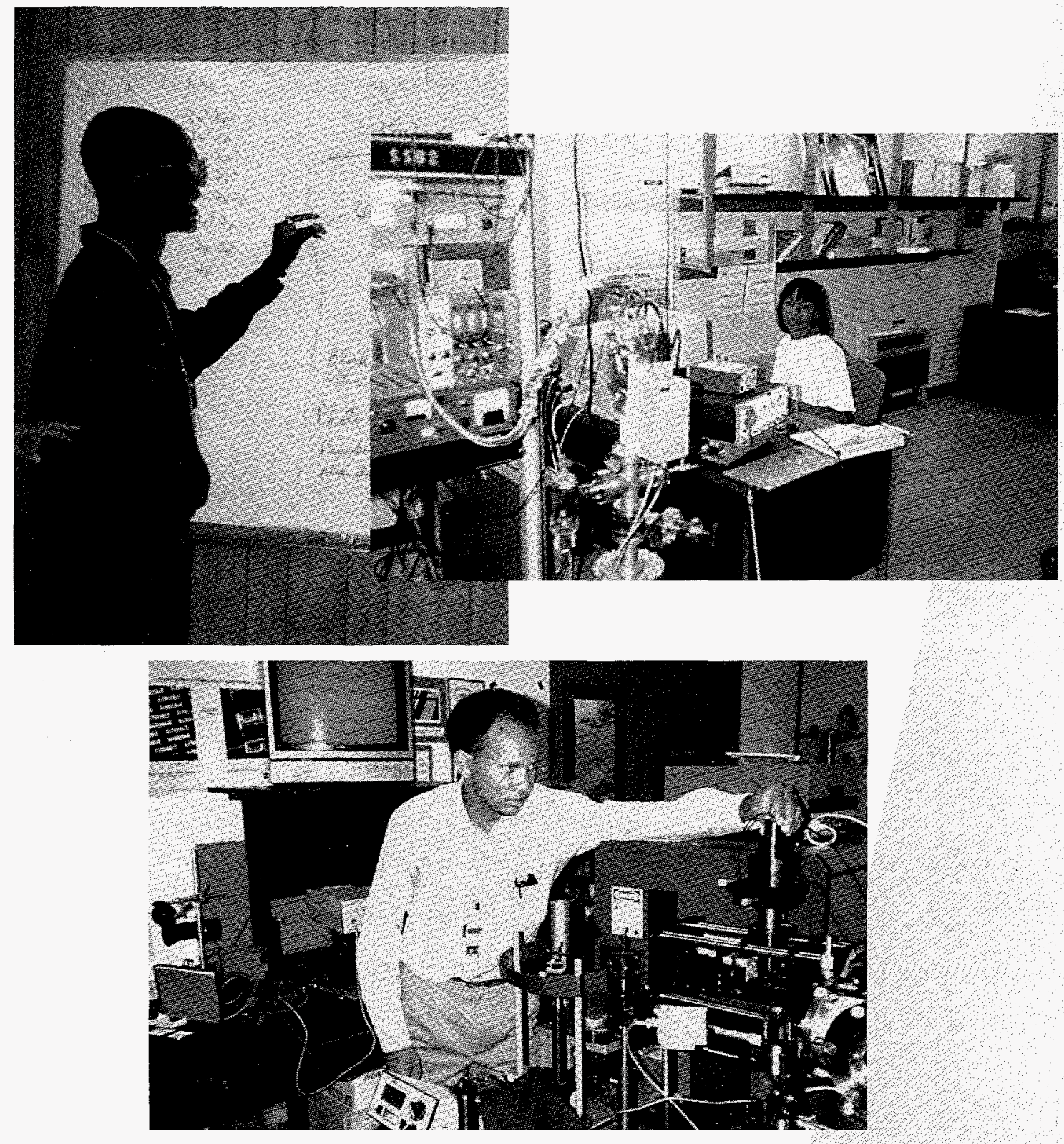




\section{Composite Information on SEA Program for FY 1994}

(Breakdown of data by race and gender available upon request)

Reporting Facility Name/Location:

Contact Name and Phone Number:

Date:

Program Name:

Brief Description:

Labs Involved:
Science and Engineering Alliance, Washington, D.C.

Dr. Robert L. Shepard (202) 842-0388 (v) (202) 842-0403 (fax) e-mail: RShepSEA@aol.com

$9 / 30 / 94$

\section{SEA Research and Education Program}

The purpose of the SEA is to enhance the research and teaching capabilities of its members, in order to provide opportunities for future scientists and engineers to become contributing participants in the nation's technical Workforce.

Lawrence Livermore National Laboratory (Sponsors Summer Internship program, Faculty, Student \& High School Teacher Travel.)

TOTAL NUMBER OF PARTICIPANTS for fiscal vear 1994

Faculty Postgrads Grad Students Undergrads H.S.Students H.S. Teachers

\begin{tabular}{|l|l|l|l|l|l|}
\hline 48 & 0 & 4 & 24 & 16 & 81 \\
\hline
\end{tabular}

A. Program Totals:

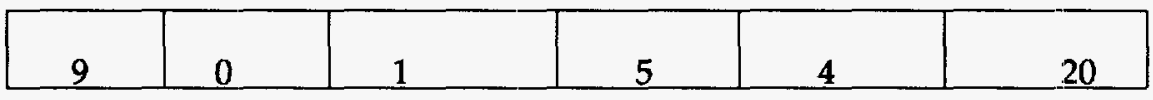

State Level Data:

State: Alabama

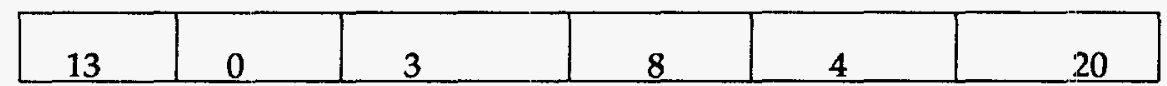

State: Mississippi

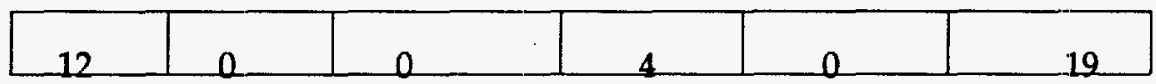

State: Texas

\begin{tabular}{|l|l|l|l|l|l|}
\hline 14 & 0 & 0 & 7 & 4 & 22 \\
\hline
\end{tabular}

State: Louisiana

\begin{tabular}{|l|l|l|l|l|l|}
\hline 0 & 0 & 0 & 0 & 1 & 0 \\
\hline
\end{tabular}

State: Maryland

\begin{tabular}{|l|l|l|l|l|l|}
\hline 0 & 0 & 0 & 0 & 3 & 0 \\
\hline
\end{tabular}




\section{SEA Scholarship and Incentive Awards Program (SIAP) 1991-94}

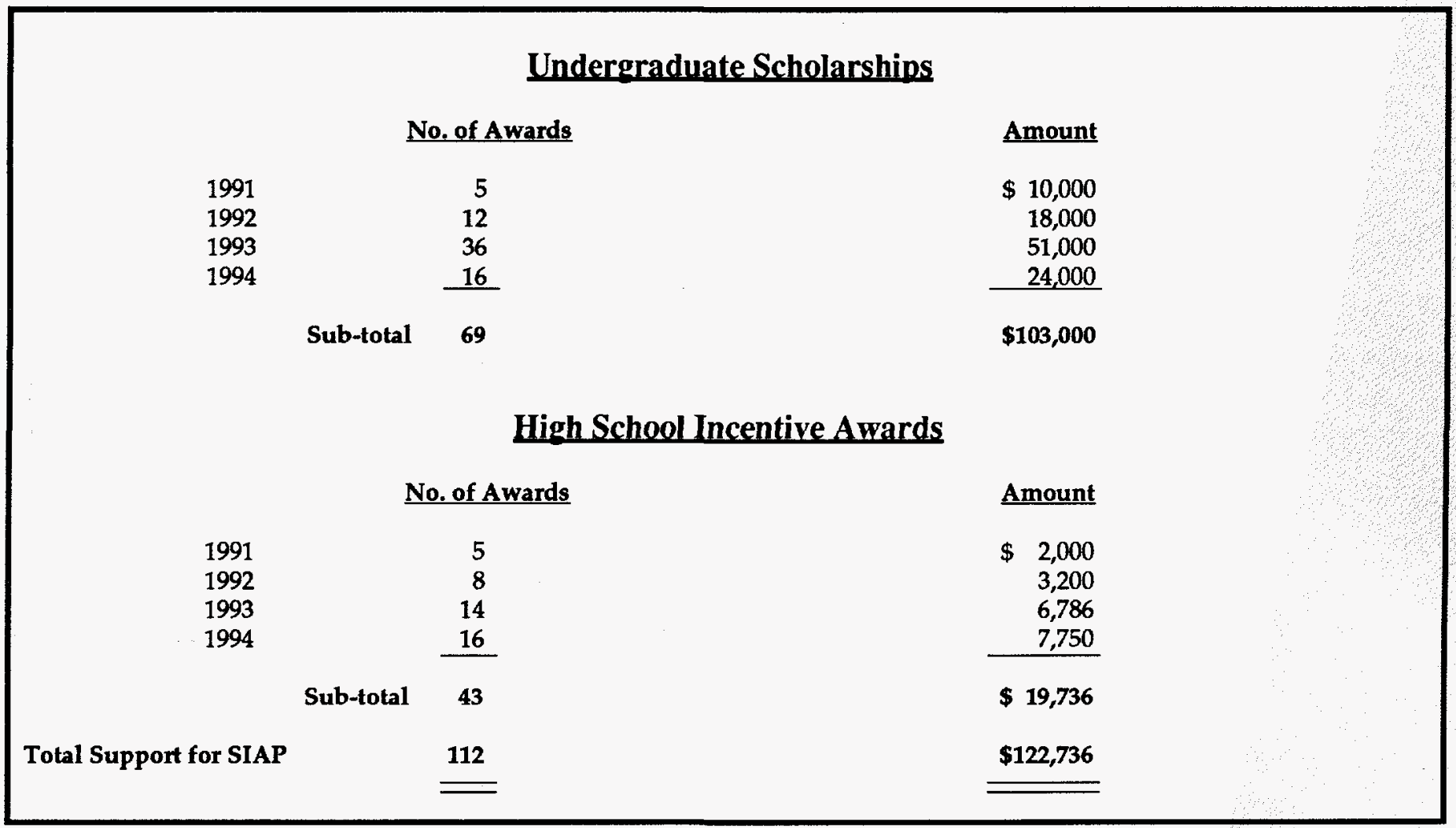

Note: SEA scholarship and incentive awards are administered in the calendar year as shown; however, all funds ane used during the academic year that coincides with SEA's fiscal year. 


\begin{tabular}{|c|c|c|c|c|c|c|c|}
\hline & $\underline{1991}$ & $\underline{1992}$ & $\underline{1993}$ & $\underline{1994}$ & $\begin{array}{r}\text { Increase } \\
\text { Over } 1993\end{array}$ & $\frac{\text { Increase }}{\text { Over } 1992}$ & $\begin{array}{l}\text { Increase } \\
\text { Over 1991 }\end{array}$ \\
\hline 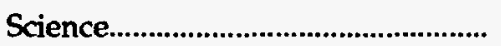 & 248 & 327 & 332 & 482 & +150 & +155 & +234 \\
\hline Engineering ${ }^{2} \ldots \ldots \ldots \ldots$ & 245 & 250 & 313 & 438 & +125 & +188 & +193 \\
\hline 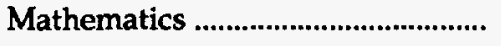 & 42 & 55 & 60 & 80 & +20 & +25 & +38 \\
\hline 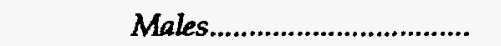 & 309 & 331 & 366 & 569 & +203 & +238 & +260 \\
\hline 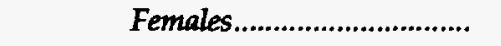 & 226 & 301 & 339 & 431 & +92 & +130 & +205 \\
\hline 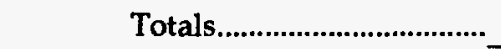 & 535 & 632 & 705 & 1000 & +295 & +368 & +465 \\
\hline
\end{tabular}

1 SOURCE: Compiled by SEA from data supplied by each member institution.

2 Includes Engineering Technology/Industrial Technology (ET/IT). ET/IT graduates continue to increase...86 in 1991,95 in 1992 , 126 in 1993, and 154 in 1994.

\section{SEA Science and Engineering Degrees Awarded in 1994 By Major and By Institution ${ }^{1}$}

\begin{tabular}{|c|c|c|c|c|c|c|c|c|c|c|c|c|c|}
\hline \multirow[b]{2}{*}{ 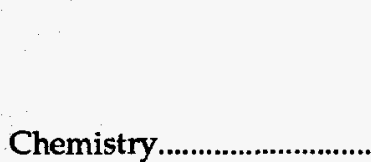 } & \multicolumn{3}{|c|}{$\begin{array}{l}\text { AAMU } \\
\text { B.S. M.S. Ph.D. }\end{array}$} & \multicolumn{3}{|c|}{$\begin{array}{c}\text { JSU } \\
\text { B.S. M.S. Ph.D. }\end{array}$} & \multicolumn{3}{|c|}{$\begin{array}{l}\text { PVAMU } \\
\text { B.S. M.S. Ph.D. }\end{array}$} & \multicolumn{3}{|c|}{$\begin{array}{l}\text { SUBR } \\
\text { B.S. M.S. Ph.D. }\end{array}$} & \multirow{2}{*}{$\begin{array}{c}\text { TOTALS } \\
39\end{array}$} \\
\hline & 7 & - & - & 11 & 2 & - & 3 & 1 & - & 7 & 8 & - & \\
\hline Biology & 29 & 3 & - & 50 & 10 & - & 59 & - & - & 18 & 4 & - & 173 \\
\hline 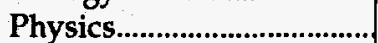 & 4 & 7 & 2 & - & - & -1 & 4 & - & - & 4 & - & - & 21 \\
\hline Physics/Meteorology........ & - & - & - & 8 & - & - & - & - & - & - & - & - & 8 \\
\hline Computer Science................ & 29 & 29 & - & 57 & 28 & - & 16 & - & - & 42 & 19 & - & 220 \\
\hline Science Education ................ & 4 & 13 & - & - & 4 & - & - & - & - & - & - & - & 21 \\
\hline 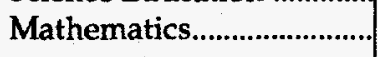 & 6 & - & - & 25 & 9 & - & 15 & 5 & - & 18 & 2 & - & 80 \\
\hline 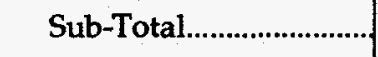 & 79 & 52 & 2 & 151 & 53 & - & 97 & 6 & - & 89 & 33 & - & 562 \\
\hline Males........................ & 33 & 31 & 2 & 77 & 30 & - & 50 & 4 & - & 37 & 15 & - & 279 \\
\hline Females.................... & 46 & 21 & - & 74 & 23 & - & 47 & 2 & - & 52 & 18 & - & 283 \\
\hline Chemical Engineering...... & - & - & - & - & - & -1 & 22 & - & - & & - & - & 22 \\
\hline Mechanical Engineering... & - & - & - & - & - & - & 44 & - & - & 23 & - & - & 67 \\
\hline Electrical Engineering....... & - & - & - & - & - & - & 101 & - & - & 51 & - & - & 152 \\
\hline Civil Engineering.................... & 10 & - & - & - & - & - & 19 & - & - & 14 & - & - & 43 \\
\hline Engineering Technology.. & 36 & - & - & - & - & - & 46 & - & - & 20 & - & - & 102 \\
\hline Industrial Technology ...... & - & 5 & - & 46 & 1 & - & - & - & - & - & - & - & 52 \\
\hline 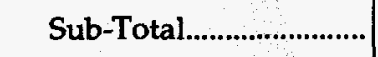 & 46 & 5 & 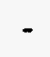 & 46 & 1 & - & 232 & - & - & 108 & - & - & 438 \\
\hline 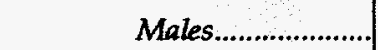 & 39 & 3 & 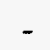 & 37 & 1 & - & 122 & - & - & 88 & - & - & 290 \\
\hline 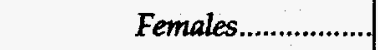 & 7 & 2 & - & 9 & - & - & 110 & - & - & 20 & - & - & 148 \\
\hline Totals........ & 125 & 57 & 2 & 197 & 54 & $=$ & 329 & 6 & - & 197 & 33 & $=$ & 1000 \\
\hline
\end{tabular}

'SOURCE: Compiled by SEA from data supplied by each member institution. 


\section{Leadership}

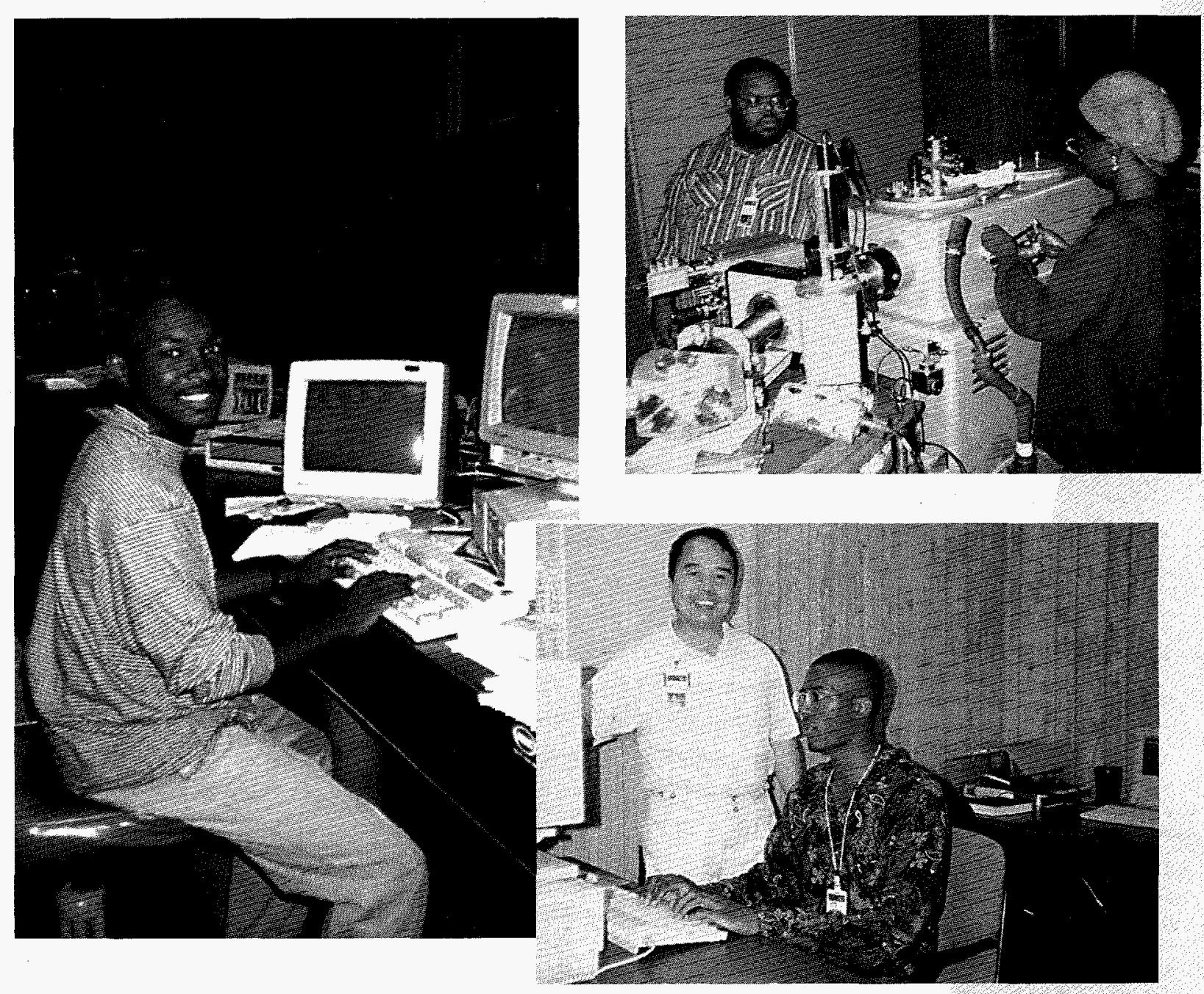




\section{Officer, Staff, Steering Committee, and Board of Directors}

\section{Officer}

Robert L. Shepard

Executive Director

Staff

Halima Adasi

Washington Coordinator

\section{Steering Committee}

Chairman

William E. Moore

Vice Chancellor for Academic Affairs

Southern University and A\&M College

Robert L Ford

Director, Center for Energy and Environ. Studies

Southern University and A\&M College

Jeanette Jones

Vice President for Research \& Development

Alabama A\&M University

Arthur Bond

Dean, School of Engineering \& Technology

Alabama A\&M University

Bettye W. Fletcher

Vice President for Research \& Development and

Dean of Graduate School

Jackson State University

Abdul Mohamed

Dean, School of Science \& Technology

Jackson State University

Willie F. Trotty

Dean, Graduate School and

Director, Research \& Sponsored Projects

Prairie View A\&M University

John Williams

Professor and Head of Chemistry Department

Prairie View A\&M University

Tommy L. Smith

Deputy Associate Director

Affirmative Action and Diversity Program

Lawrence Livermore National Laboratory

\section{Board of Directors}

Chairman

Marvin L. Yates

Chancellor, Southern University and A\&M

College

David B. Henson

President, Alabama A\&M University

James E. Lyons, Sr.

President, Jackson State University

Charles A. Hines

President, Prairie View A\&M University

Ronald Cochran

Laboratory Executive Officer

Lawrence Livermore National Laboratory

Robert L. Shepard

Executive Director, SEA, Inc.

\section{Past SEA Chairmen}

1992-1994

Gen. Julius W. Becton, Jr.

Retired Educator

1991-1992

Herman B. Smith

Retired Educator

1990-1991

James A. Hefner

President, Tennessee State University 
This Annual Report was produced by the SEA, as a guide to the activities in fiscal year 1994 . The report also serves as an account of work sponsored by the U.S. Department of Energy (DOE) under Subcontract No. L3000025. For more information, send e-mail to rshepsea@aol.com, or call (202) 842-0388, or write to the executive director, Science and Engineering Alliance, 1522 K Street, N.W., Suite 210, Washington, D.C. 20005ه

\section{Legend:}

Science and Engineering Alliance $\quad \rightarrow$ SEA

Alabama A\&M University

Jackson State University

$\rightarrow$ AAMU

Prairie View A\&M University

$\rightarrow$ JSU

Southern University and A\&M College

$\rightarrow$ PVAMU

$\rightarrow$ SUBR

Lawrence Livermore National Laboratory

$\leadsto$ LLNL

Historically Black Colleges and Universities $\rightarrow$ HBCUs

U.S. Environmental Protection Agency $\rightarrow$ EPA

U.S. Department of Energy

$\infty$ DOE 
SCIENCE AND ENGINEERING ALLIANCE, INC.

1522 K Street, N.W., Suite 210

Washington, D.C. 20005

(202) 842-0388

FAX (202) 842-0403

e-mail: rshepsea@aol.com

Design \& Layout by SEA Headquarters

Printed by Lawrence Livermore National Laboratories 